\title{
Flavor partition and fat reduction in cheese by supercritical fluid extraction: processing variables
}

\author{
Jessica L. YEE ${ }^{\mathrm{a}}$, Hany KHALIL ${ }^{\mathrm{b}}$, Rafael JiMÉNEZ-FLORES ${ }^{\mathrm{a} *}$ \\ a Department of Dairy Science, Dairy Products Technology Center, California Polytechnic State \\ University, San Luis Obispo, 1 Grand Avenue, San Luis Obispo, CA, 93407, USA \\ ${ }^{\mathrm{b}}$ Department of Food Science and Nutrition, California Polytechnic State University, San Luis Obispo, \\ 1 Grand Avenue, San Luis Obispo, CA, 93407, USA
}

\begin{abstract}
Developing low-fat cheese with flavor to match that of full-fat cheese has been a challenge in the dairy industry. The objective of this investigation was to develop lower fat Cheddar and Parmesan grated cheese using supercritical fluid extraction (SFE) and characterize its flavor profile comparative to a full-fat product. Specifically, enabling flavor compound partition between the matrices of cheese and extracted lipids. Carbon dioxide $\left(\mathrm{CO}_{2}\right)$ was the supercritical fluid for fat extraction. Extraction took place in a $500 \mathrm{~mL}$ SFE vessel using $100 \mathrm{~g}$ of grated cheese. Fractional factorial design was utilized to investigate two levels of treatment for each pressure (200 and 350 bar), temperature $\left(35\right.$ and $40{ }^{\circ} \mathrm{C}$ ) and $\mathrm{CO}_{2}$ level $(500$ and $1000 \mathrm{~g}$ ) for each extraction trial. The most efficient parameters for lipid removal resulted in $51.00 \%$ fat reduction (wet basis) for Cheddar extracted at $200 \mathrm{bar}, 40{ }^{\circ} \mathrm{C}, 1000 \mathrm{~g} \mathrm{CO}_{2}$, and $55.56 \%$ fat reduction for Parmesan extracted at $350 \mathrm{bar}$, $35^{\circ} \mathrm{C}, 1000 \mathrm{~g} \mathrm{CO}_{2}$. Thin layer chromatography (TLC) was utilized to assess the lipid composition of each cheese and the lipids extracted by SFE. TLC analysis for Cheddar and Parmesan cheeses showed only nonpolar lipids (triaclyglycerides and free fatty acids) in the recovered lipids extracted by SFE; indicating that polar lipids such as phospholipids are being retained in the cheese matrix. Gas chromatography/mass spectroscopy techniques were used to characterize volatile flavor compounds for each cheese sample. SFE treatment of the cheeses altered the ability to detect flavor compounds and allowed partitioning of those compounds, which varied with the type of cheese. This study suggests that SFE technology can be used in the dairy industry to develop cheese products lower in fat, which retain flavor compounds that may not be typically fully developed with alternative methods of low-fat cheese processing.
\end{abstract}

supercritical fluid extraction / carbon dioxide / Parmesan cheese / Cheddar cheese / fat

摘要 - 超临界流体萃取技术用于干酪风味的隔离和减脂: 加工过程的变量。开发低 脂肪干酪且保持全脂干酪风味的技尔已经成为乳品工业中富有挑战性的研究内容。 本研究目的是采用超临界流体萃取技术研究低脂肪的契达干酪和 Parmesan 碎干酪, 并 将其风味特性与全脂干酪进行了对比, 特别是有可能将风味化合物在干酪基质和抽 提出的脂肪之间隔离开。二氧化碳是超临界流体萃取脂肪的流体。将 $100 \mathrm{~g}$ 粉碎的 干酪放入 $500 \mathrm{~mL}$ 的超临界流体萃取器内进行萃取, 每个处理的分馏参数分别设计成 2 个水平, 这些参数分别为压力 $(200 、 350 \mathrm{bar})$ 、温度 $\left(35 、 40{ }^{\circ} \mathrm{C}\right)$ 和二氧化碳水平

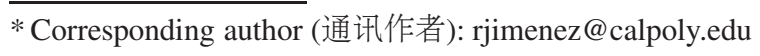


$(500 \mathrm{~g} 、 1000 \mathrm{~g})$ 。在 $200 \mathrm{bar} 、 40{ }^{\circ} \mathrm{C}$ 和 $1000 \mathrm{~g} \mathrm{CO}_{2}$ 的条件下, 该方法可以从契达干酪中抽提 出 $51.00 \%$ 脂肪（湿基）; 在 $350 \mathrm{bar} 、 35^{\circ} \mathrm{C} 、 1000 \mathrm{~g} \mathrm{CO}_{2}$ 条件下, 从 Parmesan干酪中抽提 出 $55.56 \%$ 的脂肪 (湿基)。采用薄层色谱法 (TLC) 测定每种干酪以及萃取出脂质后干酪的 脂质组成。根据对契达干酪和 Parmesan 干酪的分析, 发现在抽提出的脂质中只存在非极性 脂 (包括甘油三酸脂和游离脂肪酸), 表明极性脂如磷脂则保留在干酪中。气相色谱 / 质谱联 用技术用于干酪中挥发性芳香化合物的表征。不同品种的干酪经超临界流体萃取处理后, 尽 管干酪风味化合物的组成和含量有所改变,但是基本上保持了干酪的风味成分。本研究证明 了超临界流体萃取技术可以应用于乳品工业中生产低脂肪干酪且可以有效地保持干酪的风 味, 认为该方法是生产低脂平酪的一种可选择性方法。

\section{超临界流体萃取 / 二氧化碳 / Parmesan干酪 / 契达干酪 / 脂肪}

Résumé - Partage des composés d'arômes et réduction de la matière grasse dans un fromage traité par extraction par fluide supercritique : variables du procédé. Développer des fromages allégés en matière grasse avec une flaveur équivalente à celle de fromages gras constitue un défi pour l'industrie laitière. L'objectif de cette recherche a été de développer des fromages râpés (Cheddar et Parmesan) allégés en matière grasse en utilisant l'extraction par fluides supercritiques (SFE) et de caractériser leur profil aromatique comparé à celui d'un fromage gras, et plus spécifiquement, d'empêcher le partage des composés de flaveur entre les matrices fromagères et les fractions lipidiques extraites. Le dioxyde de carbone $\left(\mathrm{CO}_{2}\right)$ a été utilisé comme fluide supercritique pour l'extraction de la matière grasse. L'extraction a été réalisée dans un récipient pour SFE de $500 \mathrm{~mL}$ en utilisant $100 \mathrm{~g}$ de fromage râpé. Un plan factoriel fractionné a été utilisé pour étudier 2 niveaux de traitement pour chaque pression (200 et 350 bar), température $\left(35\right.$ et $\left.40{ }^{\circ} \mathrm{C}\right)$ et niveau de $\mathrm{CO}_{2}(500$ et $1000 \mathrm{~g}$ ) pour chaque essai d'extraction. L'efficacité maximale de séparation des lipides a été obtenue en utilisant les paramètres d'extraction suivants : $200 \mathrm{bar}, 40{ }^{\circ} \mathrm{C}, 1000 \mathrm{~g}$ de $\mathrm{CO}_{2}$, permettant d'obtenir $51,00 \%$ de réduction de la matière grasse (base sèche) pour le Cheddar, et 350 bar, $35^{\circ} \mathrm{C}$ et $1000 \mathrm{~g}$ de $\mathrm{CO}_{2}$ pour une réduction de matière grasse de 55,56\% pour le Parmesan. La chromatographie sur couche mince a été utilisée pour évaluer la composition lipidique de chaque fromage et les lipides extraits par SFE. Les analyses chromatographiques des fromages Cheddar et Parmesan ont montré que seuls des lipides non polaires (triacylglycérides et acides gras libres) étaient présents dans la partie lipidique extraite, indiquant que les lipides polaires comme les phospholipides étaient retenus dans la matrice fromagère. Les techniques de chromatographie gazeuse couplée à la spectrométrie de masse ont été utilisées pour caractériser les composés aromatiques volatils de chaque échantillon de fromage. Le traitement SFE des fromages a altéré la possibilité de détecter les composés d'arômes et a permis la séparation de ces composés, mais de façon variable selon le type de fromage. Cette étude suggère que la technique SFE peut être utilisée dans l'industrie laitière pour développer des fromages allégés en matière grasse qui retiennent les composés d'arômes, ce qui peut ne pas être obtenu par d'autres techniques de fabrication de fromages allégés en matière grasse.

extraction par fluide supercritique / dioxyde de carbone / Parmesan / Cheddar / matière grasse

\section{INTRODUCTION}

Due to the increased consumption of dietary fat in industrialized nations, the development of coronary heart disease, some types of cancer and obesity are problems now more commonly seen in adults and children $[7,8,12]$. Therefore, consumer demand for low-fat food choices has been steadily increasing, but consumers are not fully willing to compromise on taste [20]. For example, in 1998 the sales of low-fat and reduced-fat cheeses in the United States was approximately $20 \%$ of supermarket sales for cheese products [13]. The challenge in low-fat cheese technology is to develop a low-fat cheese that would retain the full-fat cheese flavor and texture. Utilizing SFE technology, it is possible to decrease the fat content in grated cheese samples. SFE technology is based on the principle that under a combination of pressure and temperature, certain chemicals such as carbon dioxide, are able to 
act as solvents for certain solutes when the solvent becomes supercritical [18]. Carbon dioxide is chosen as an ideal solvent for fat extraction; its low critical temperature allows lipids to be removed from the food without being thermally degraded during processing [17]. Supercritical fluid extraction has been used to extract aromas and total fat from cheeses. Previous studies used SFE to identify and quantify volatile fractions of unsmoked Idiazábal ewe's milk cheese [9]. Roncal cheese aromatic extracts were also obtained by SFE, at extraction conditions of $50{ }^{\circ} \mathrm{C}$ and 109 bar and $20 \mathrm{~min}$ for the static and dynamic phase. In addition, sensory methods (ranking, similarity and matching tests) were utilized to assess how representative were the aromatic extracts [10]. SFE has additionally allowed for the determination of total fat and fat-soluble vitamins in Parmigiano cheese and salami; SFE was statistically equivalent to the Soxhlet extraction method for determining total fats [15]. There are official methods using supercritical fluid extraction, such as the determination of total fat in oily seeds [1], with possibilities for expanding the use of SFE technology for different analytical purposes or for food processing. There has been little research investigating SFE as a process for developing low-fat cheeses, therefore this will be the focus of this research paper. Unlike typical low-fat cheese formulation, this approach starts with fully matured cheese. The goal of this work was to determine how the supercritical fluid extraction process affects fat removal and cheese flavor in relation to the type of cheese treated.

\section{MATERIALS AND METHODS}

\subsection{Experimental design}

Variable parameters of the process were pressure (200 bar, 350 bar), temperature $\left(35{ }^{\circ} \mathrm{C}, 40{ }^{\circ} \mathrm{C}\right)$, amount of $\mathrm{CO}_{2}(500 \mathrm{~g}$, $1000 \mathrm{~g}$ ), the flow rate was kept constant at $20 \mathrm{~g} \cdot \mathrm{min}^{-1}$, and cheese type (Cheddar and Parmesan). A $2^{4}$ fractional factorial design was utilized to investigate $2 \mathrm{lev}$ els of each variable. The experiment was run over a period of eight days with six runs performed each day. The first four days consisted of the Cheddar cheese treatments; eight randomized treatment levels with three replicates, the same procedure was applied for Parmesan cheese samples the last 4 days of processing.

\subsection{Sample preparation}

Commercial Cheddar cheese aged over 9 months in 2-lb blocks and commercial grated Parmesan cheese aged over 10 months were purchased in 3-lb bags. Approximately $100 \mathrm{~g}$ of hand grated Cheddar cheese and grated Parmesan cheese were weighed on an analytical balance (Mettler Toledo AB204, Columbus, Ohio, USA) separately and evenly distributed into filter bags (Filter Fabrics Incorporated, Goshen, IN), sealing both ends of the bag. After processing, the cheese sample was removed from the filter bag and reweighed to determine percent loss of cheese weight after extraction. The extracted fat was collected in $50-\mathrm{mL}$ falcon tubes after each trial and saved for further analysis.

\subsection{Supercritical fluid extraction}

The SFE unit used was a laboratory scale SFE system (model SFE 500; Thar Technologies, Inc., Pittsburgh, PA) with an extraction volume of up to $500 \mathrm{~mL}$, maximum flow rate of $50 \mathrm{~g} \cdot \mathrm{min}^{-1}$, maximum operating pressure of $600 \mathrm{bar}$, maximum temperature of $150{ }^{\circ} \mathrm{C}$, cyclone separator capacity of $500 \mathrm{~mL}$, including an automated back pressure regulator (model BPR A-200B). The carbon dioxide tanks used for extraction were supplied by Air Gas 
(50-lb., San Luis Obispo, CA). The process unit was operated at the dynamic mode, which allowed the sample to be continuously supplied with fresh supercritical fluid and the extracted analytes were constantly swept into the collection device [6].

\subsection{Cheese compositional analysis}

\subsubsection{Fat content}

The percent fat content (wet basis) of all full-fat and SFE treated Cheddar and Parmesan cheese samples were determined by the Babcock method for cheese as per Standard Methods for the Examination of Dairy Products [3] in triplicate.

\subsubsection{Lipid characterization}

Thin layer chromatography was used to chemically analyze the lipid profile of the cheeses and lipids extracted from SFE processing. Fat analysis by the Mojonnier was used to obtain the lipid samples for each cheese as per Standard Methods for the Examination of Dairy Products [3]. Each lipid sample was diluted with chloroform: methanol (1:2) solvent mixture to a $10 \mathrm{mg} \cdot \mathrm{mL}^{-1}$ concentration and was applied with capillary tubes (Drummond Scientific Co., Broomall, PA). Polar standards phosphatidyl ethanolamine, phosphatidyl choline and sphingomyelin (Sigma Chemicals Co., St. Louis, MO) were spotted on the plates at $1 \mathrm{mg} \cdot \mathrm{mL}^{-1}$ concentration to detect specific phospholipids in the cheese sample. Polar and nonpolar plates were run to characterize the lipid fractions, such as phospholipids, cholesterol and fatty acids remaining in the cheese. Pre-coated silica gel plates $20 \times 20 \mathrm{~cm}$ in size was used (EMD Chemicals Inc., Gibbstown, NJ) for separation. The plates were placed in either a polar solvent tank consisting of chloroform:methanol:water (65:25:4, v/v), or nonpolar solvent tank consisting of petroleum ether:ethyl ether:glacial acetic acid $(85: 15: 2, \mathrm{v} / \mathrm{v})$. The plates were developed with iodine (Sigma Chemicals Co., St. Louis, MO) until spots on the plate become dark enough for visual analysis. All plates were scanned using a densitometer (Model GS-700 Imaging Densitometer, Bio Rad Hercules, California, USA).

\subsubsection{Moisture content}

The moisture content was measured before and after SFE processing using the AOAC International methods for cheese; 977.11 microwave oven [14] utilizing a LabWave 9000 Microwave Moisture/Solids Analyzer (CEM Corporation, Matthews, North Carolina), programmed for the appropriate method parameters, for either Cheddar or Parmesan Cheese. Approximately two to three $g$ of sample was needed for each analysis conducted in triplicate.

\subsection{Flavor analysis}

Water soluble volatile flavor compounds in commercial reduced-fat, full-fat, SFE treated, and fat extracted by SFE were analyzed for both Cheddar and Parmesan cheeses. The SFE treated cheese samples consisted of Cheddar cheese extracted at 200 bar, $40{ }^{\circ} \mathrm{C}, 1000 \mathrm{~g} \mathrm{CO}_{2}$, and Parmesan extracted at 350 bar, $35{ }^{\circ} \mathrm{C}$, $1000 \mathrm{~g} \mathrm{CO}_{2}$; the most efficient levels of fat removal for each type of cheese. Analysis using Gas Chromatography/Mass Spectroscopy (PerkinElmer Instruments Autosystem XL Gas Chromatograph, Turbomass Mass Spec Shelton, CT, USA) with a column $30 \mathrm{~m}$ in length and $0.25 \mathrm{~mm}$ I.D. and a 4560 O.I. Analytical Sample Concentrator (Purge and Trap) was employed, using helium as the carrier gas 
(flow rate: $40 \mathrm{~mL} \cdot \mathrm{min}^{-1}$ ). The temperature program included starting analysis at $35{ }^{\circ} \mathrm{C}$ for $7 \mathrm{~min}$, after which temperature increased to $245^{\circ} \mathrm{C}$ at $6{ }^{\circ} \mathrm{C} \cdot \mathrm{min}^{-1}$. The GC samples were prepared by combining the cheese sample and water to make a slurry consisting of a 1:2 cheese to water ratio in a 4 ounce whirl-pak bag, then placed in a stomacher for $5 \mathrm{~min}$. The resulting $10 \mathrm{~mL}$ slurry was placed in a glass borosilicate tube $(18 \times 150 \mathrm{~mm}$ VWR Scientific) covered with parafilm then analyzed immediately. The lipid samples collected from the SFE trials were also analyzed. Five milliliters of the extracted cheese lipid was mixed with $5 \mathrm{~mL}$ of water in a test tube; the $10 \mathrm{~mL}$ solution was covered with parafilm until GC analysis.

Identification of volatile sulfur compounds in full-fat, SFE treated and commercial reduced-fat cheeses for Cheddar and Parmesan cheeses were also investigated. Volatile sulfur compounds in the Cheddar and Parmesan cheese samples were determined using headspace solid-phase microextraction and gas chromatograph-pulsed flame photometric detection (SPME-GC-PFPD). Sample preparation and flavor compound analysis was conducted as described by Burbank and Qian [4].

\subsection{Sensory analysis}

Sensory evaluation studies were conducted in order to determine the organoleptic effects that supercritical fluid extraction had on the cheeses. Cheeses treated at $35{ }^{\circ} \mathrm{C}, 350$ bar, $1000 \mathrm{~g} \mathrm{CO}_{2}$ were used for the study, resulting in SFE Cheddar samples containing approximately $18 \%$ fat, and SFE Parmesan cheese samples approximately $20 \%$ fat. A triangle discrimination test was used to determine if the original grated cheese product and the SFE product cold be differentiated in any way [11]. The panelists were asked to choose the version that is the most different from the other two [11]. This test would determine if there were any significant differences between the two products based on flavor. To determine the acceptability of the SFE processed cheese versus a full-fat version and a commercial cheese product $(21.5 \%$ fat for commercial reduced-fat Cheddar, $20 \%$ fat for commercial reduced-fat Parmesan), sensory analysis was conducted using a 9point hedonic sensory test. A 9-point hedonic scale with scores ranging from 1 being 'dislike extremely', 5 being 'neither like nor dislike', to 9 being 'like extremely' was used for scoring. The tests were administered in the sensory evaluation area located on the campus's Food Processing building at California Polytechnic State University, San Luis Obispo. Forty untrained panelists were involved in the study and were selected at random. The age range of the panelists was between 18-45, and the gender distribution was approximately $42 \%$ males and $58 \%$ females.

\subsection{Statistical analysis}

A multivariate analysis of variance (MANOVA) was used to analyze the differences in the responses fat loss, moisture gain, and weight loss based on changes in the experimental variables temperature, pressure, $\mathrm{CO}_{2}$ level, and cheese type, and their two-way interactions. Since the experiment was run over $8 \mathrm{~d}$, day was used as a blocking factor in the analysis. Because the cheese type was not randomly assigned, the day factor was nested within cheese type.

\section{RESULTS AND DISCUSSION}

\subsection{Compositional analysis}

The mean values for percent fat (wet basis), percent moisture and percent weight 


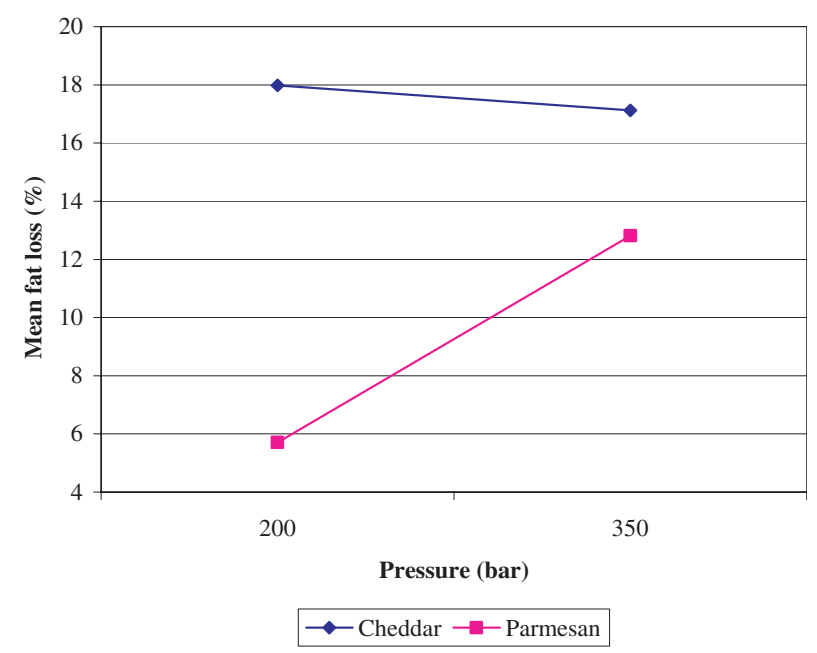

Figure 1. The influence of pressure level change on predicted mean fat loss for Cheddar and Parmesan cheeses. loss after extraction at different pressure, temperature and $\mathrm{CO}_{2}$ trials are summarized in Table I. $P$-values were calculated for each combination of response and experimental variable to determine whether the experimental variable had a significant effect. These results are shown in Table II. Because of the large number of tests (33), each $P$-value was compared to 0.01 , instead of the traditional 0.05 , in order to protect against incorrect claims of significance. Overall, cheese type and pressure had a significant effect on all three responses, $\mathrm{CO}_{2}$ level only affected weight loss and temperature did not significantly affect any of the responses.

\subsubsection{Efficiency of fat extraction}

The effect of the processing parameters on the percent fat removed from the cheese was variety and pressure dependent, which affected fat loss interactively $(P<0.0001)$. Carbon dioxide amounts did not significantly affect fat loss. Figure 1 shows the influence of pressure level change on predicted mean fat loss for Cheddar and Parmesan cheeses, actual values are found in Table III. The data model for the predicted mean fat loss for both types of cheese at the two pressure levels showed that we expect to see a large difference between fat lost at 200 bar to 350 bar for Parmesan cheese samples, losing more fat at higher pressures. However the predicted model for the Cheddar cheeses seemed not to differ as greatly. The differences in mean fat loss at various pressure levels among cheese types and within each cheese type was also evaluated, pair-wise comparisons can be seen in Table IV. The results show a greater difference in mean fat loss in Cheddar cheese than in Parmesan cheese at both 200 bar $(P<0.0001)$ and 350 bar of pressure $(P<0.0001)$. It is important to note that Cheddar cheese had a higher initial fat content compared to Parmesan cheese (about 9.62\% more fat), therefore Cheddar consequentially had higher amounts of fat removed when compared to Parmesan. The differences in mean fat loss increased significantly from $5.7 \%$ to $12.8 \%$ in Parmesan cheese when the pressure was changed from 200 bar to 350 bar $(P<0.0001)$. Therefore there is a tremendous pressure affect on the amount of fat removed, just by increasing the pressure when treating Parmesan cheese. However, there was no 
Table I. Fat content, moisture content (\%) of full-fat and supercritical fluid extracted Cheddar and Parmesan cheeses at different pressure, temperature and carbon dioxide trials.

\begin{tabular}{lccccc}
\hline Cheese variety & $\begin{array}{c}\text { Temperature } \\
\left({ }^{\circ} \mathrm{C}\right)\end{array}$ & $\begin{array}{c}\text { Pressure } \\
(\text { bar })\end{array}$ & $\begin{array}{c}\text { Carbon Dioxide } \\
(\mathrm{g})\end{array}$ & $\begin{array}{c}\text { Fat }^{\mathrm{b}} \\
(\%)\end{array}$ & $\begin{array}{c}\text { Moisture }^{\mathrm{c}} \\
(\%)\end{array}$ \\
\hline Cheddar (Control) & ${\mathrm{N} / \mathrm{A}^{\mathrm{a}}}^{\mathrm{a}}$ & $\mathrm{N} / \mathrm{A}^{\mathrm{a}}$ & $\mathrm{N} / \mathrm{A}^{\mathrm{a}}$ & $36.06 \pm 0.34$ & $34.87 \pm 0.59$ \\
Cheddar & 35 & 200 & 500 & $18.25 \pm 0.25$ & $42.57 \pm 0.83$ \\
Cheddar & 35 & 200 & 1000 & $18.17 \pm 0.29$ & $40.66 \pm 1.01$ \\
Cheddar & 35 & 350 & 500 & $18.50 \pm 0.00$ & $42.55 \pm 1.05$ \\
Cheddar & 35 & 350 & 1000 & $18.17 \pm 0.29$ & $41.64 \pm 1.40$ \\
Cheddar & 40 & 200 & 500 & $18.17 \pm 0.24$ & $42.00 \pm 0.89$ \\
Cheddar & 40 & 200 & 1000 & $17.67 \pm 0.29$ & $40.66 \pm 1.54$ \\
Cheddar & 40 & 350 & 500 & $19.67 \pm 0.14$ & $40.78 \pm 1.51$ \\
Cheddar & 40 & 350 & 1000 & $19.42 \pm 0.14$ & $39.79 \pm 1.15$ \\
\hline Parmesan (Control) & $\mathrm{N} / \mathrm{A}^{\mathrm{a}}$ & $\mathrm{N} / \mathrm{A}^{\mathrm{a}}$ & $\mathrm{N} / \mathrm{A}^{\mathrm{a}}$ & $26.44 \pm 0.30$ & $29.74 \pm 0.50$ \\
Parmesan & 35 & 200 & 500 & $20.50 \pm 0.29$ & $30.11 \pm 0.92$ \\
Parmesan & 35 & 200 & 1000 & $19.50 \pm 0.50$ & $29.39 \pm 1.05$ \\
Parmesan & 35 & 350 & 500 & $14.42 \pm 0.24$ & $31.93 \pm 0.56$ \\
Parmesan & 35 & 350 & 1000 & $11.75 \pm 0.54$ & $31.99 \pm 0.67$ \\
Parmesan & 40 & 200 & 500 & $21.58 \pm 0.52$ & $29.16 \pm 0.29$ \\
Parmesan & 40 & 200 & 1000 & $21.00 \pm 0.71$ & $28.49 \pm 1.32$ \\
Parmesan & 40 & 350 & 500 & $15.33 \pm 0.29$ & $34.01 \pm 0.42$ \\
Parmesan & 40 & 350 & 1000 & $13.00 \pm 0.00$ & $32.20 \pm 0.43$ \\
\hline
\end{tabular}

${ }^{a}$ N/A pertaining to full-fat Cheddar or Parmesan cheeses with no SFE treatment.

b Mean averaged by trial for Babcock analysis (wet basis) in triplicate.

${ }^{c}$ Mean averaged by trial for microwave oven moisture analysis in triplicate.

Table II. Multivariate analysis of variance for fat loss, moisture gain and weight loss after supercritical fluid extraction; $P$-values of statistical tests $(\alpha=0.01)$.

\begin{tabular}{llcc}
\hline & \multicolumn{3}{c}{$P$-values for } \\
\cline { 2 - 4 } Source & Fat loss & Moisture gain & Weight loss \\
\hline Cheese & $0.0001^{*}$ & $0.0002^{*}$ & $0.0001^{*}$ \\
Temp. & 0.5144 & 0.0262 & 0.6234 \\
Pressure & $0.0001^{*}$ & 0.1852 & $0.0001^{*}$ \\
$\mathrm{CO}_{2}$ & 0.0590 & 0.0235 & $0.0082^{*}$ \\
Cheese*Temp. & 0.0131 & 0.8915 & 0.2866 \\
Cheese*Pressure & $0.0001^{*}$ & $0.0001^{*}$ & $0.0081^{*}$ \\
Temp.*Pressure & 0.0492 & 0.0904 & 0.1017 \\
Cheese* $\mathrm{CO}_{2}$ & 0.0277 & 0.0363 & 0.0350 \\
Temp. $\mathrm{CO}_{2}$ & 0.0260 & 0.4439 & 0.0296 \\
Pressure* $\mathrm{CO}_{2}$ & 1.0000 & 0.3175 & 0.8606 \\
Day & $0.0009 *$ & $0.0033^{*}$ & 0.0643 \\
\hline
\end{tabular}

* Significant at $P<0.01$. 
Table III. Predicted mean percentage fat loss on wet basis as it correlates with pressure level and cheese type.

\begin{tabular}{lcc}
\hline Pressure level (Bar) & Cheese type & Mean fat loss \\
\hline 200 & Cheddar & 17.99 \\
200 & Parmesan & 5.71 \\
350 & Cheddar & 17.13 \\
350 & Parmesan & 12.82 \\
\hline
\end{tabular}

Table IV. Differences in mean fat loss at various pressure levels among cheese types and within each cheese type.

\begin{tabular}{llccl}
\hline Pressure treatment & & Difference & Standard error & $P$-value \\
\hline 200 bar, Parmesan - & 200 bar, Cheddar & -12.28 & 0.24980 & $0.0000^{*}$ \\
350 bar, Cheddar - & 200 bar, Cheddar & -0.85 & 0.41800 & 0.2616 \\
350 bar, Cheddar - & 200 bar, Parmesan & 11.42 & 0.24980 & $0.0000^{*}$ \\
350 bar, Parmesan - & 200 bar, Cheddar & -5.17 & 0.24980 & $0.0000^{*}$ \\
350 bar, Parmesan - & 200 bar, Parmesan & 7.10 & 0.15800 & $0.0000^{*}$ \\
350 bar, Parmesan - & 350 bar, Cheddar & -4.32 & 0.24980 & $0.0000^{*}$ \\
\hline
\end{tabular}

* Significant at $P<0.01$.

significant change in the differences in mean fat loss for Cheddar cheese when pressure was increased from 200 to 350 bar $(P=0.26)$, therefore there is less affect of pressure in the extraction of fat from Cheddar cheeses.

The initial average percent fat in the Cheddar cheese was $36.06 \%$ (wet basis). The maximum amount of fat extracted for Cheddar resulted in a final fat content of $17.67 \%$ (51.00\% fat reduction). Those values were obtained at processing parameters of $40{ }^{\circ} \mathrm{C}, 200$ bar and $1000 \mathrm{~g} \mathrm{CO}_{2}$. Parmesan cheese had an average initial percent fat level of $26.44 \%$, with a maximum fat extraction of $11.75 \%$ (55.56\% fat reduction). Parmesan cheese experienced the maximum amount of fat extracted at $35^{\circ} \mathrm{C}$, 350 bar and $1000 \mathrm{~g} \mathrm{CO}_{2}$. Overall, at least $45.45 \%$ of the fat was reduced form the Cheddar samples and $18.38 \%$ of the fat from the Parmesan cheese samples at lowest fat extraction trials. When compared on a dry weight basis, Cheddar cheese showed a $46.27 \%$ reduction in fat at the most efficient levels of extraction, and Parmesan cheeses resulted in $54.13 \%$ fat reduction.
The Codex Alimentarius Commission provides guidelines for the declaration of milkfat content in the general standard for cheese, which is reported as a percentage of fat in dry matter (FDM) [5]. Therefore according to these standards, at the highest levels of fat extraction SFE Cheddar cheese could be considered medium fat cheese since the FDM is above or equal to $25 \%$ and less than $45 \%$ (29.78\% FDM). The SFE parmesan cheese could be classified as partially skimmed cheese since the FDM is above or equal to $10 \%$ and less than $25 \%(17.26 \%)$. Further optimization of the SFE process can be performed to obtain the desired level of fat content to meet specific label claims.

\subsubsection{Selectivity of lipid extraction}

The effect of supercritical fluid extraction on minor lipids, which influences consumer perception of flavor [13], was evaluated using thin layer chromatography (TLC). Figure 2 indicates that for SFE Cheddar samples (lanes 2-9), all of the 


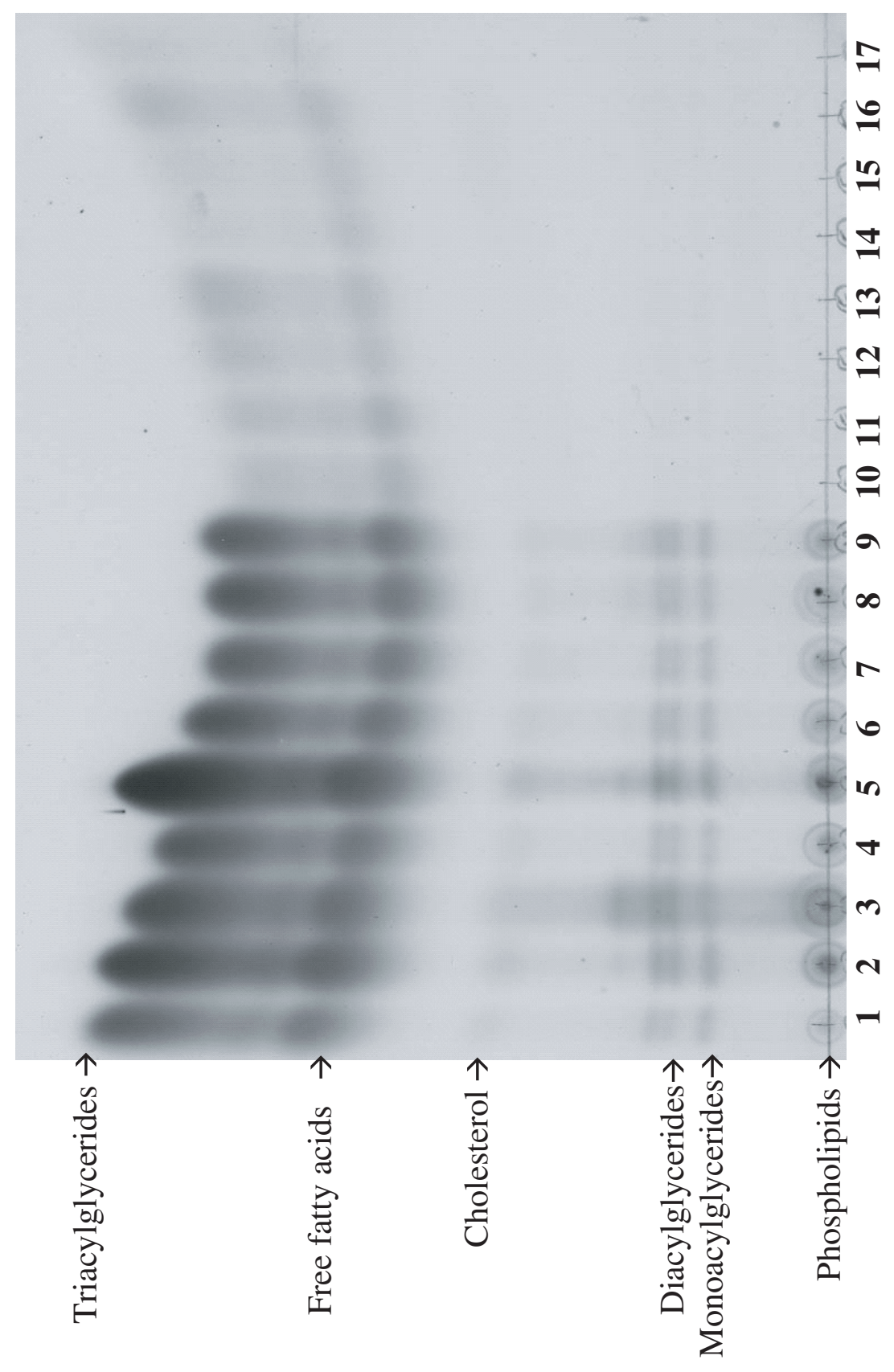

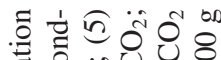
त्ञ

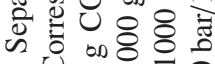
U.

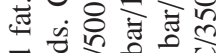

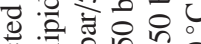

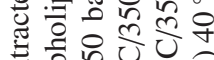
× क्रित0 떰웡 至

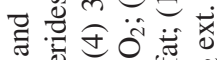

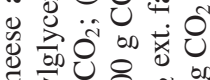
บ J on 0 됟 n 00 bo t)

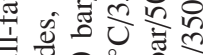
串 8000

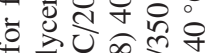

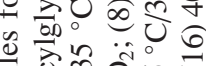
픙 0 的

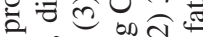
뭄 $\exists$ U 唃 ษ 웡 u

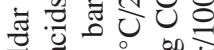
웡ㅇㅇㅇㅛ 吾 卷出 히워

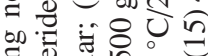

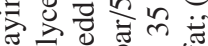

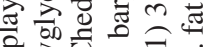

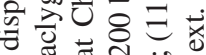
可萧芯

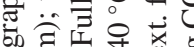
की है क्षे 붕

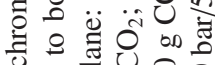
은 80 氙 毛密 F

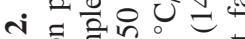

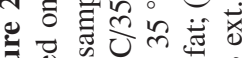

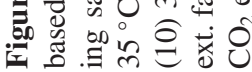




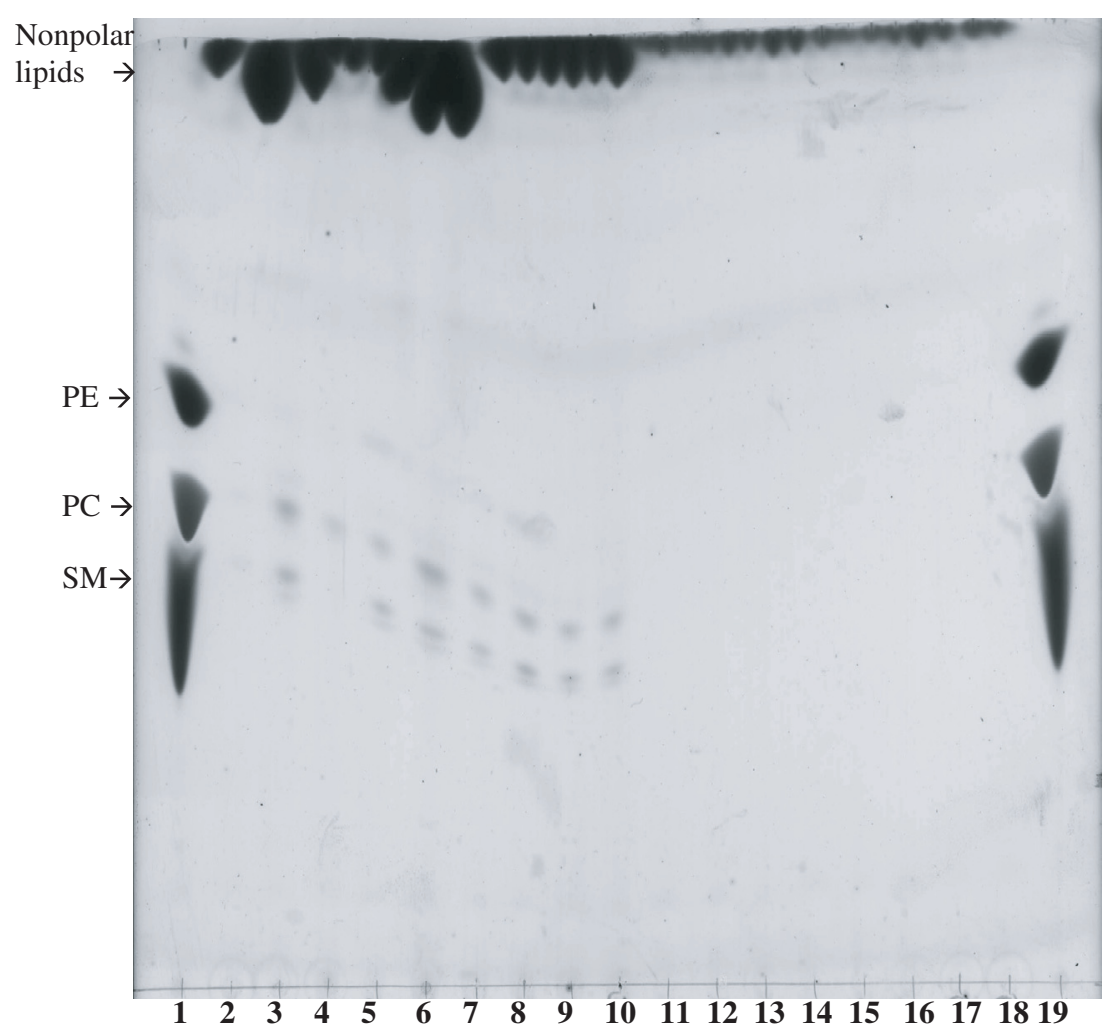

Figure 3. Thin layer chromatograph displaying polar Cheddar cheese lipid profiles for full-fat, SFE cheese and SFE extracted fat. Separation based on polarity (top to bottom); nonpolar lipids, phosphatidyl ethanolamine (PE), phosphatidyl choline (PC) and sphingomyelin (SM). Corresponding samples for each lane: (1) Polar lipid standard mix (PC, PE, SM); (2) Full-fat Cheddar; (3) $35{ }^{\circ} \mathrm{C} / 200 \mathrm{bar} / 500 \mathrm{~g} \mathrm{CO}_{2}$; (4) $35{ }^{\circ} \mathrm{C} / 200 \mathrm{bar} / 1000 \mathrm{~g} \mathrm{CO}_{2}$; (5) $35{ }^{\circ} \mathrm{C} / 350 \mathrm{bar} / 500 \mathrm{~g}$ $\mathrm{CO}_{2}$; (6) $35{ }^{\circ} \mathrm{C} / 350 \mathrm{bar} / 1000 \mathrm{~g} \mathrm{CO}_{2}$; (7) $40{ }^{\circ} \mathrm{C} / 200 \mathrm{bar} / 500 \mathrm{~g} \mathrm{CO}_{2}$; (8) $40{ }^{\circ} \mathrm{C} / 200 \mathrm{bar} / 1000 \mathrm{~g}$ $\mathrm{CO}_{2}$; (9) $40{ }^{\circ} \mathrm{C} / 350 \mathrm{bar} / 500 \mathrm{~g} \mathrm{CO}_{2}$; (10) $40{ }^{\circ} \mathrm{C} / 350 \mathrm{bar} / 1000 \mathrm{~g} \mathrm{CO}_{2}$; (11) $35{ }^{\circ} \mathrm{C} / 200 \mathrm{bar} / 500 \mathrm{~g}$ $\mathrm{CO}_{2}$ ext. fat; (12) $35{ }^{\circ} \mathrm{C} / 200$ bar/1000 $\mathrm{g} \mathrm{CO} \mathrm{CO}_{2}$ ext. fat; (13) $35{ }^{\circ} \mathrm{C} / 350$ bar/500 $\mathrm{g} \mathrm{CO}_{2}$ ext. fat; (14) $35{ }^{\circ} \mathrm{C} / 350 \mathrm{bar} / 1000 \mathrm{~g} \mathrm{CO} 2$ ext. fat; (15) $40{ }^{\circ} \mathrm{C} / 200$ bar $/ 500 \mathrm{~g} \mathrm{CO}_{2}$ ext. fat; (16) $40{ }^{\circ} \mathrm{C} / 200$ bar/1000 g CO$~_{2}$ ext. fat; (17) $40{ }^{\circ} \mathrm{C} / 350$ bar/500 $\mathrm{g} \mathrm{CO}_{2}$ ext. fat; (18) $40^{\circ} \mathrm{C} / 350 \mathrm{bar} / 1000 \mathrm{~g} \mathrm{CO}_{2}$ ext. fat; (19) polar lipid standard mix (PE, PC, SM).

lipids in the SFE cheeses had been concentrated, however the extracted fat from SFE (lanes 10-17) only contained triaclyglycerides and free fatty acids, therefore confirming that only nonpolar lipids are being removed during extraction. The more polar phospholipids were retained in the cheese matrix. This is shown by the phospholipid spots bound to the origin where the sam- ples were applied (lanes 2-9) in Figure 2. To observe phospholipid retention in the cheese matrix, phospholipid standards consisting of the three main milk fat globule membrane phospholipids were used; phosphatidyl ethanolamine, phosphatidyl choline and sphingomyelin [19]. Figure 3 shows that compared to the full-fat Cheddar sample (lane 2), phospholipids had 
been concentrated in the SFE treated Cheddar cheese samples (lanes 2-10), and there was no phospholipids in the extracted fat (lanes 11-18). The SFE Cheddar cheese samples contained all three of the phospholipids in the polar standard, in lower concentrations. The nonpolar and polar Parmesan cheese plates demonstrated very similar results as the Cheddar cheese plates, only differing slightly in the visualization of the phospholipids in the Parmesan SFE cheese, therefore illustrations of these plates were not included.

TLC analysis on the various cheeses samples confirms the hypothesis that there are no phospholipids leaving the cheese matrix along with the extracted fat, and only nonpolar lipids are being removed. This effect has also been seen in the increased concentration of phospholipids in buttermilk powder samples by microfiltration and SFE, where SFE selectively removed only nonpolar lipid material from the buttermilk product and the extracted lipids had no residual polar lipids [2]. This is significant from a nutritional standpoint because phospholipids have many health related benefits [19]. Therefore, the retention of these fats in cheese may provide added benefit to consumers in addition to lowering the overall fat content in the product.

\subsubsection{Moisture content}

Table I displays the moisture content of cheese before and after SFE processing. Cheddar cheese moisture content reached $42.57 \%$ from an initial moisture content of $34.87 \%$. Full-fat Parmesan cheese had an initial moisture content of $29.74 \%$ which increased to $34.01 \%$ after SFE. The cheese type and pressure also affected moisture gain interactively $(P<0.0001)$, see Table II. The percentage of moisture most likely increased due to fat removal and the resultant change in the proportion of weight of water to the total weight.

\subsubsection{Flavor profile analysis}

Figure 4 shows a comparison of the total number of water soluble flavor compounds made among selected samples. These included each type of cheese before and after processing; a commercial reducedfat product; and fat extracted by SFE. Removal of fat with supercritical carbon dioxide resulted in a higher number of flavors detected in the cheeses matrix. Therefore, the change in the composition of each cheese after SFE allowed for easier detection of flavors. This was especially seen with SFE Cheddar cheese samples, as well as slight increases in the number of flavor compounds in SFE Parmesan samples. Regardless of the type of cheese, the extracted lipid fractions showed the highest amount of flavor compounds detected compared to either full-fat or SFE treated cheeses. Extraction of lipids by SFE resulted in partition of flavors between the cheese matrix and the lipids extracted, however it was unexpected that the extracted cheese sample would allow for a higher number of flavor compounds detected. In addition, commercial reduced-fat products of Cheddar and Parmesan cheeses was analyzed to see the number of water soluble compounds detected as a starting baseline for comparison. Both commercial Cheddar and Parmesan cheeses did not differ greatly from the full-fat cheese, however more compounds were detected in both SFE Parmesan and Cheddar cheeses, see Figure 4.

The use of solid phase microextraction and gas-chromatograph pulse flame photometric detection allowed for detection of various volatile sulfur compounds in the cheese samples. An example chromatogram for full-fat Cheddar cheese before extraction and the SFE cheese can be seen in Figures 5 and 6 . Overall, similar compounds could be detected such as carbonyl sulfide, hydrogen sulfide, methanethiol, carbon disulfide, dimethyl sulfide, dimethyl disulfide, 


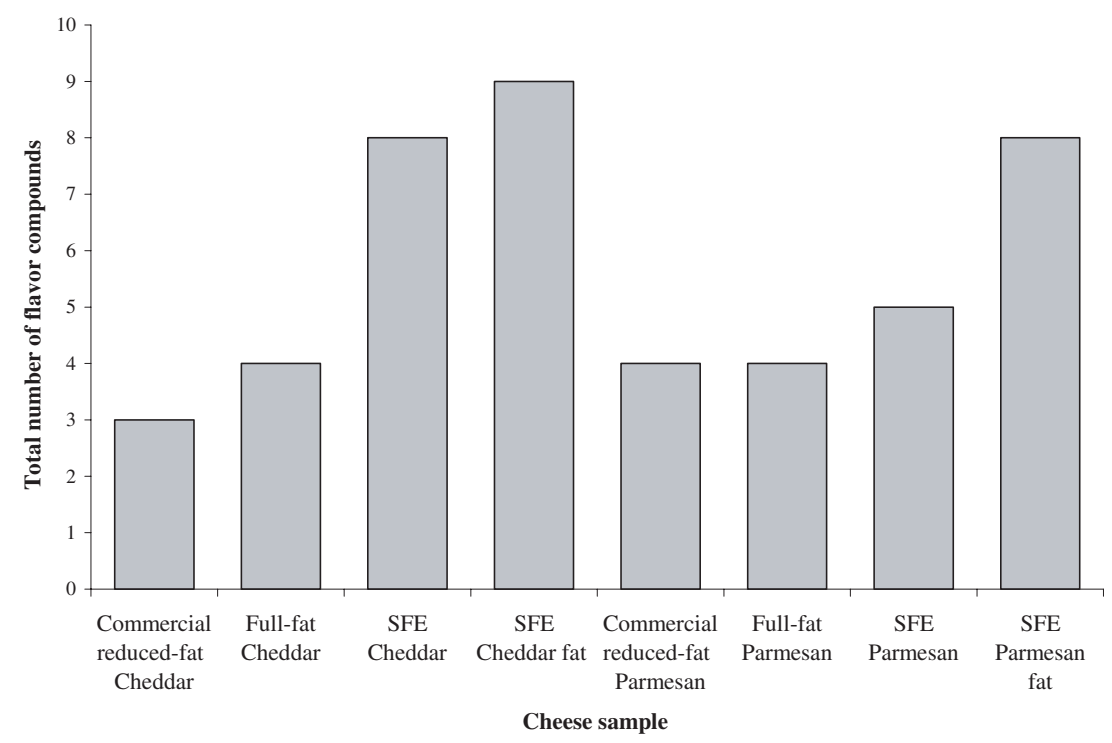

Figure 4. Comparison of the total number of water soluble flavor compounds by GC-MS analysis for commercial reduced-fat, full-fat, SFE treated and SFE extracted lipids for Cheddar and Parmesan cheese.

ethyl thioacetate, dimethyl trisulfide, methional, and dimethyl sulfone. However after extraction, two additional volatile sulfur compounds consisting of dimethyl trisulfide and methional were also detected. Figures 7 and 8 summarize and compare the volatile flavor compounds detected in fullfat, SFE treated and commercial reducedfat Cheddar and Parmesan cheeses. The relative intensity of volatile sulfur compounds increased after supercritical fluid extraction in Cheddar cheeses. For example, hydrogen sulfide, methanethiol, carbon disulfide, dimethyl disulfide, and dimethyl trisulfide increased relative to full-fat Cheddar and most of the commercial reduced-fat sample. In addition, methional a major contributor in cheese aroma was actually detected after SFE [16], which was not detected in the full-fat Cheddar cheeses or commercial reducedfat samples. However, dimethyl sulfide levels decreases, whereas carbonyl sulfide, ethyl thioacetate and dimethyl sulfone did not change after extraction. SFE treated
Parmesan cheese had slightly higher concentrations of methanethiol and methional, but lower in hydrogen sulfide, dimethyl sulfide, dimethyl disulfide, dimethyl trisulfide, ethyl thioacetate, dimethyl sulfone did not change after extraction. Methionol was not detected in either full-fat or SFE Parmesan cheeses, but found in the commercial reduced-fat product. Analysis of commercial reduced-fat products allowed for comparison of the volatile sulfur compounds in cheeses formulated with lower amounts of fat. Sulfur compound profiles between the SFE and full-fat cheeses had a higher degree of similarity, than between the full-fat and commercial reduced fat cheeses. Even though similar flavors were detected, the relative levels of the compounds identified differed greatly.

The causes of the variation in partition of flavor in the two types of cheeses after SFE, may be explained by polarity of flavor compounds in various lipid fractions. The level of volatile compounds in the cheese following SFE may be due to their 


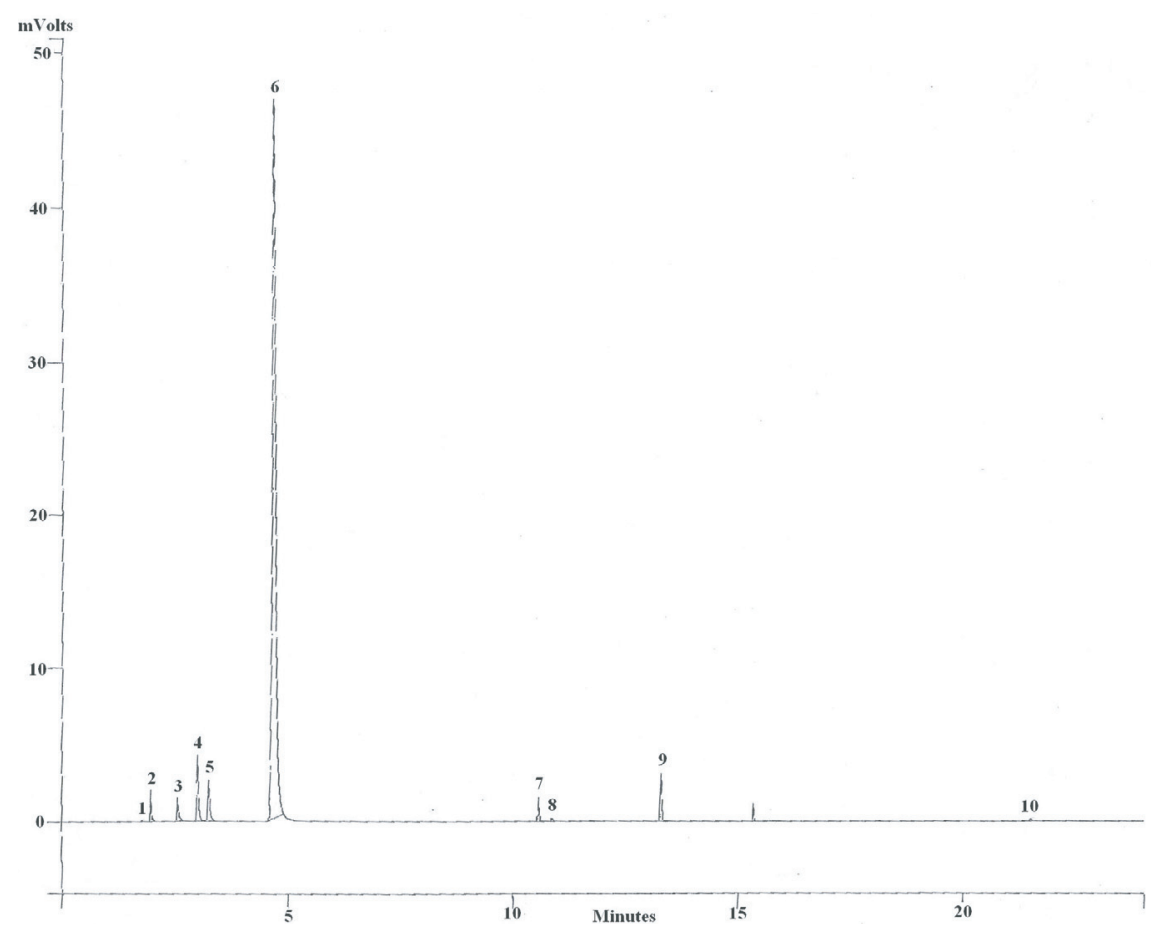

Figure 5. Chromatogram of sulfur profile for full-fat Cheddar cheese using solid phase microextraction gas-chromatograph pulsed flame photometric detection. Volatile sulfur compounds are as follows: 1 = carbonyl sulfide, 2 = hydrogen sulfide, 3 = methanethiol, 4 = carbon disulfide, $5=$ dimethyl sulfide, $6=$ ethyl methyl sulfide (internal standard), $7=$ dimethyl disulfide, $8=$ ethyl thioacetate, $9=2$-methylpropanal (internal standard), $10=$ dimethyl sulfone.

relative stability and mechanism of degradation as a function of temperature, carbon dioxide level and pressure; however the exact mechanism is not fully understood. Further investigation is needed to characterize the changes in volatile flavor compounds after SFE treatment of cheese.

\subsection{Sensory evaluation}

A cross population of forty panelists were used for discrimination and preference testing.

The results of our triangle discrimination test were based on comparing our values with those of a binomial distribution table [11]. The triangle difference test in- dicated that $70 \%$ of the panelists could tell the difference between the full-fat and SFE Cheddar cheese. This clearly indicates that in the case of Cheddar cheese the process altered the flavor and consistency.

However, panelists could not discriminate between the Parmesan full-fat and SFE processed cheese. Only $45 \%$ of panelist could distinguish between full-fat and SFE Parmesan cheese. This could indicate that the extraction process in Parmesan did not significantly change the panelists' flavor perception in the cheese. The scores for the 9-point hedonic test were statistically analyzed by a one-way ANOVA test $\left(\right.$ MINITAB $^{\circledR}$ Release 14 program) at a 95\% confidence 


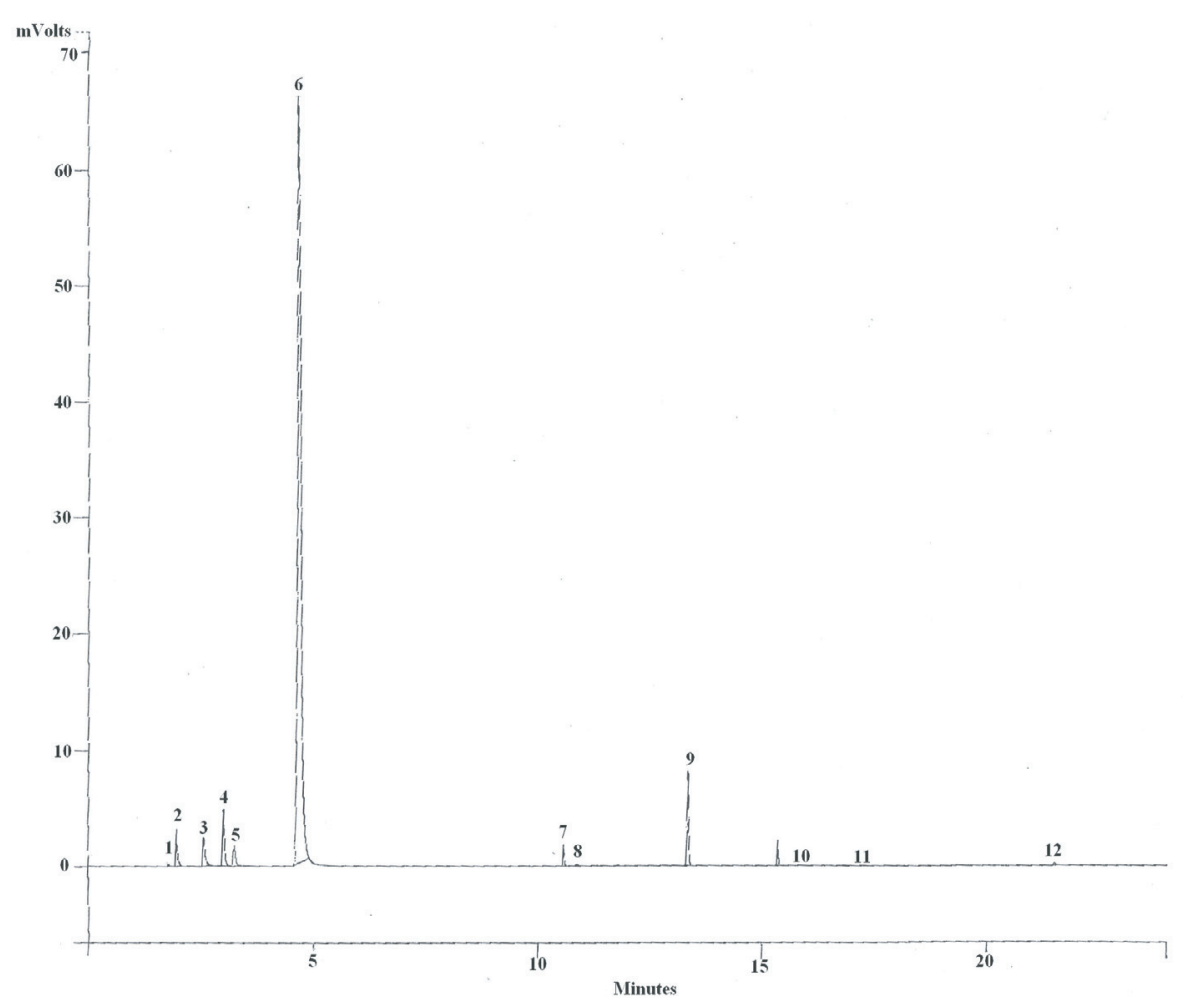

Figure 6. Chromatogram of sulfur profile for Cheddar supercritical fluid extracted cheese using solid phase microextraction gas-chromatograph pulsed flame photometric detection. Volatile sulfur compounds are as follows: $1=$ carbonyl sulfide, $2=$ hydrogen sulfide, $3=$ methanethiol, $4=$ carbon disulfide, 5 = dimethyl sulfide, $6=$ ethyl methyl sulfide (internal standard), $7=$ dimethyl disulfide, 8 = ethyl thioacetate, $9=2$-methylpropanal (internal standard), $10=$ dimethyl trisulfide, $11=$ methional, 12 = dimethyl sulfone.

level. The mean acceptability of Cheddar cheese samples were not equal $(P$ value $=0.03)$. The full-fat Cheddar and commercial reduced-fat Cheddar had close means of 6.325 and 6.375 respectively; however the SFE Cheddar had a mean score of 5.45. This indicates that panelists did not equally prefer all three Cheddar samples. The mean acceptability of the full-fat Parmesan, SFE Parmesan and commercial reduced-fat Parmesan were equal $(P$-value $=0.374)$, indicating no significant difference in the mean scores. Surprisingly, the SFE Parmesan samples received a mean score of 5.625 which was higher than scores for the full-fat version at 5.05 and the commercial reduced-fat product at 5.0. This indicates that panelist actually preferred the SFE parmesan product to the other products tested. In summary, the panelists found the treatment easily identifiable in Cheddar cheese, while in Parmesan they could not significantly tell the difference.

\section{CONCLUSION}

Supercritical fluid extraction from mature Cheddar and Parmesan cheeses 


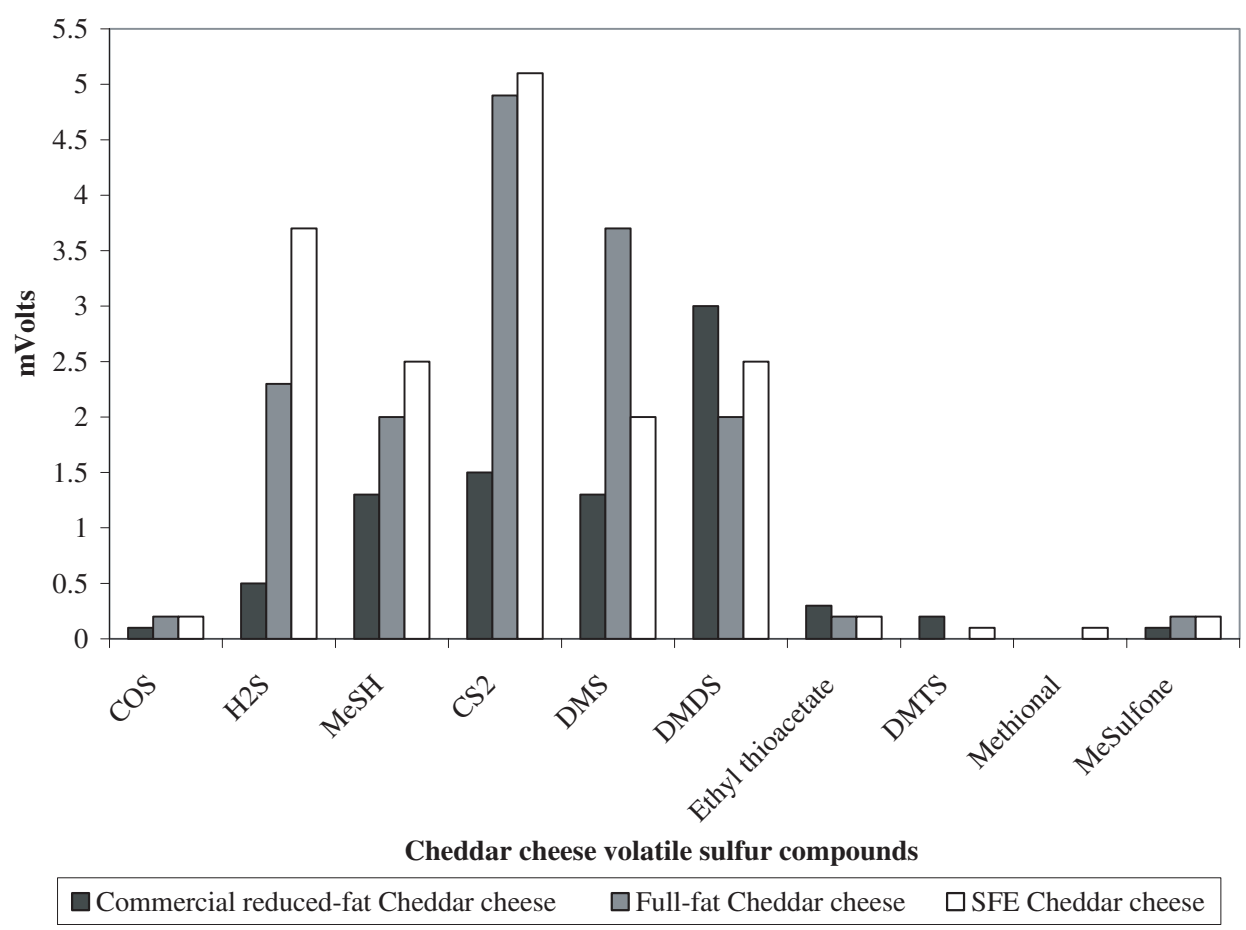

Figure 7. Comparison of volatile sulfur compounds detected by solid phase microextraction gaschromatograph pulsed flame photometric detection for commercial reduced-fat Cheddar, full-fat, and SFE treated Cheddar cheese using chromatogram peak areas (mVolts). Left to right: carbonyl sulfide (COS), hydrogen sulfide (H2S), methanethiol (MeSH), carbon disulfide (CS2), dimethyl sulfide (DMS), dimethyl disulfide (DMDS), ethyl thioacetate, dimethyl trisulfide (DMTS), methional, dimethyl sulfone (MeSulfone).

allowed for the reduction in total fat, with no need for modification in formulation. Lipid extraction depended on cheese matrix. Under the conditions tested we achieved a maximum fat reduction of $51.00 \%$ for Cheddar cheese, and $55.56 \%$ fat reduction for Parmesan cheese (wet basis). For Cheddar cheese the process was independent of temperature and pressure between 200 to 350 bar and $35^{\circ} \mathrm{C}$ to $40{ }^{\circ} \mathrm{C}$. Parmesan cheese pressure had a significant effect on extraction. Extraction in both cheeses was selective for the removal of nonpolar lipids, whereas polar lipids remained entirely in the cheese. Initial flavor analysis on the cheeses clearly indicated that supercritical fluid extraction altered the detection of water soluble and volatile sulfur flavor compounds. As lipids were liberated from the cheese matrix, we detected more cheese flavors and/or higher concentrations in the samples treated by SFE. This could have an effect on how flavor is perceived by a consumer, if some volatile flavor compounds are more easily perceived after a cheese has been processed by SFE. Sensory tests provided information on whether consumers could perceive the change in SFE cheeses, and how acceptable the final product was to 


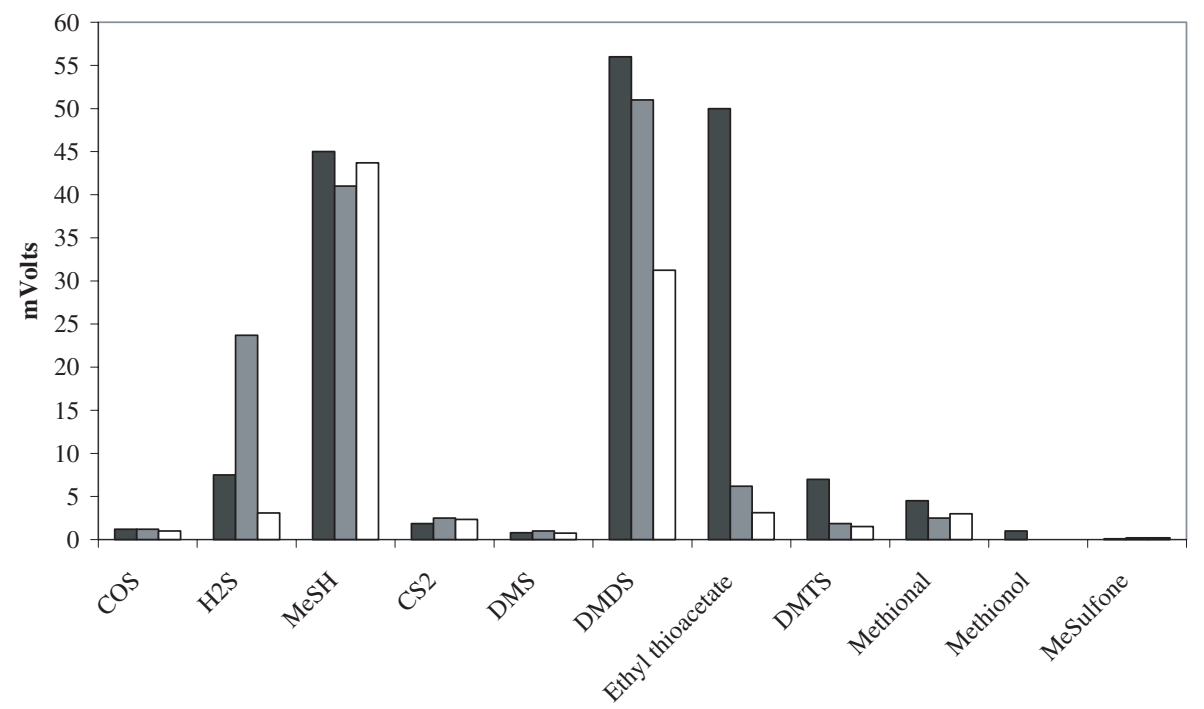

Parmesan cheese volatile sulfur compounds

Commercial reduced-fat Parmesan cheese $\quad \square$ Full-fat Parmesan cheese $\quad \square$ SFE Parmesan cheese

Figure 8. Comparison of volatile sulfur compounds detected by solid phase microextraction gaschromatograph pulsed flame photometric detection for commercial reduced-fat Parmesan full-fat, and SFE treated Parmesan cheeses using chromatogram peak areas (mVolts). Left to right: carbonyl sulfide (COS), hydrogen sulfide (H2S), methanethiol (MeSH), carbon disulfide (CS2), dimethyl sulfide (DMS), dimethyl disulfide (DMDS), ethyl thioacetate, dimethyl trisulfide (DMTS), methional, methionol, dimethyl sulfone (MeSulfone).

the panelists compared to other products. Sensory evaluation for discrimination tests indicated that panelists could identify the difference between the full-fat and SFE Cheddar cheese treated samples, but could not differentiate between the Parmesan samples. Preference tests similarly, indicated that panelists actually preferred the SFE treated Parmesan sample $(24.36 \%$ fat reduced) to the full-fat and commercial reduced-fat samples. Descriptive sensory analysis may help to better characterize attributes of the SFE cheeses perceived by panelists. Based on these results, we suggest that supercritical fluid extraction is a valuable tool to study fat reduction and flavor partition in cheese. Furthermore, the supercritical fluid extraction process has a great potential in commercial applications.
Acknowledgements: Funding provided by the Dairy Management, Inc., the California State University Agricultural Research Initiative and the California Dairy Research Foundation. We thank Dr. J. Walker, Dr. M. Qian, Dr. N. Farkye, H. Burbank and M. Arnold for their contributions to this research.

\section{REFERENCES}

[1] AOCS, Official Methods and Recommended Practice of the American Oil Chemists Society, 1996, Methods Ai 3.75, Am 3.96.

[2] Astaire J.C., Ward R., German J.B., JimenezFlores R., Concentration of polar MFGM lipids from buttermilk by microfiltration and supercritical fluid extraction, J. Dairy Sci. 86 (2003) 2297-2307.

[3] Bradley R.L.J., Arnold E., Barbano D.M., Semerad R.G., Smith D.E., Vines B.K., 
Chemical and Physical Methods: Fat, in: Marshall R.T. (Ed.), Standard Methods for the Examination of Dairy Products, 16 edn., American Public Health Association, Washington, 1992, p. 433-531.

[4] Burbank H.M., Qian M., Volatile sulfur compounds in Cheddar cheese determined by headspace solid-phase microextraction and gas chromatograph-pulsed flame photometric detection, J. Chromatogr. A 1066 (2005) 149-157.

[5] Codex Alimentarius Commission, Codex General Standard for Cheese: CODEX STAN A-6-1978, Rev.1-1999, Amended 2006.

[6] Hawthorne S.B., Methodology for off-line Supercritical Fluid Extraction, in: Westwood S.A. (Ed.), Supercritical Fluid Extraction and Its Use in Chromatographic Sample Preparation, Chapman \& Hall, Boca Raton, 1993, p. 39-64.

[7] Hursting S.D., Thornquist M., Henderson M.M., Types of dietary fat and the incidence of cancer at five cites, Prev. Med. 19 (1990) 242.

[8] Kris-Etherton P.M., Krummel D., Russel M.E., Dreon D., Mackey S., Borchers J., Wood P.D., The effect of diet on plasma lipids, lipoproteins, and coronary heart disease, J. Am. Diet. Assoc. 88 (1988) 13731400 .

[9] Larrayoz P., Carbonell M., Ibanez F., Torre P., Barcina Y., Optimization of indirect parameters which affect the extractability of volatile aroma compounds from Idiazabel cheese using analytical supercritical fluid extractions (SFE), Food Chem. 64 (1999) 123127.

[10] Larrayoz P., Ibanez F.C., Ordonez A.I., Torre P., Barcina Y., Evaluation of supercritical fluid extraction as sample preparation for the study of Roncal cheese aroma, Int. Dairy J. 10 (2000) 755-759.
[11] Lawless H.T., Heymann H., Sensory Evaluation of Food Principles and Practices, Kluwer Academic/Plenum Publishers, New York, 1998.

[12] Miller W.C., Lindeman A.K., Wallace J., Niederpruen M., Diet composition, energy intake, and exercise in relation to body fat in men and women, Am. J. Clin. Nutr. 52 (1990) 426-430.

[13] Mistry V.V., Low fat cheese technology, Int. Dairy J. 11 (2001) 413-422.

[14] Nielsen S.S., Moisture and Total Solids Analysis, in: Bradley R.L.J. (Ed.), Food Analysis, Kluwer Academic/Plenum Publishers, New York, 2003, p. 81-101.

[15] Perretti G., Marconi O., Montanari L., Paolo F., Rapid determination of total fats and fatsoluble vitamins in Parmigiano cheese and salami by SFE, Lebensm.-Wiss. u.-Technol. 37 (2004) 87-92.

[16] Qian M.C., Reineccius G.A., Identification of aroma compounds in ParmigianoReggiano cheese by gas chromatography/olfactometry, J. Dairy Sci. 85 (2003) 1362-1369.

[17] Rizvi S., Yu Z., Bhashkar A., Chidambara R.C., Fundamentals of Processing with Supercritical Fluids, in: Supercritical Fluid Processing of Food and Biomaterials, Chapman \& Hall, Bishopbriggs, Glasgow, 1994, p. 1-26.

[18] Rozzi N.L., Singh R.K., Supercritical Fluids and the Food Industry, Compr. Rev. Food Sci. Food Saf. 1 (2002) 33-34.

[19] Spitsberg V.L., Bovine milk fat globule membrane as a potential nutraceutical, J. Dairy Sci. 88 (2005) 2289-2294.

[20] Williams C., Consumer considerations in reduced fat foods, in: Mela D.J. (Ed.), Dietary Fats: Determinants of Preference, Selection and Consumption, Elsevier applied science, London/New York, 1992, pp. 179-192. 